\title{
History of Wireless Communication
}

Tom Seymour, Minot State University, USA

Ali Shaheen, Minot State University, USA

\begin{abstract}
The history of communication is an exciting topic. This article reviews various areas that makeup the current history of wireless communication. These topics include: the wireless vision, generations of wireless, technical issues, current wireless systems, wireless LaNs, Wide Area Wireless Data Services, Broadband Wireless Access, Satellite Wireless Access, Satellite Networks, and Bluetooth and this material will stimulate you to do more research in these various areas of the wireless industry.
\end{abstract}

Keywords: Wireless; Communication; History; Wireless Systems; Bluetooth

\section{INTRODUCTION}

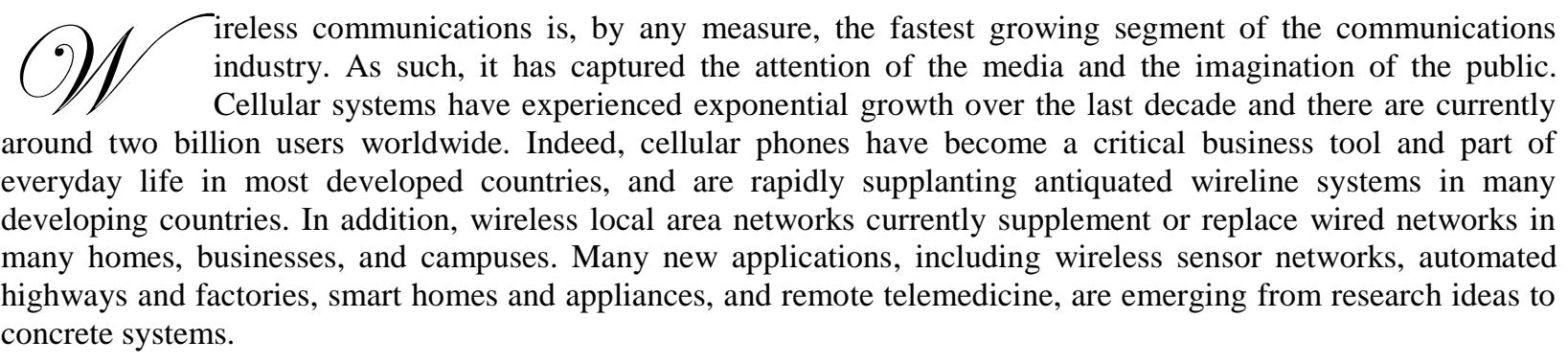

\section{HISTORY OF WIRELESS COMMUNICATIONS}

The first wireless networks were developed in the Pre-industrial age. These systems transmitted information over line-of-sight distances (later extended by telescopes) using smoke signals, torch signaling, flashing mirrors, signal flares, or semaphore flags. An elaborate set of signal combinations was developed to convey complex messages with these rudimentary signals. Observation stations were built on hilltops and along roads to relay these messages over large distances. These early communication networks were replaced first by the telegraph network (invented by Samuel Morse in 1838) and later by the telephone. In 1895, a few decades after the telephone was invented, Marconi demonstrated the first radio transmission from the Isle of Wight to a tugboat 18 miles away, and radio communications was born. The first network based on packet radio, ALOHANET, was developed at the University of Hawaii in 1971. This network enabled computer sites at seven campuses spread out over four islands to communicate with a central computer on Oahu via radio transmission. The network architecture used a star topology with the central computer at its hub. The U.S. military was extremely interested in the combination of packet data and broadcast radio inherent to ALOHANET. Throughout the 1970's and early 1980's the Defense Advanced Research Projects Agency (DARPA) invested significant resources to develop networks using packet radios for tactical communications in the battlefield.

Packet radio networks also found commercial application in supporting wide-area wireless data services. These services, first introduced in the early 1990's, enable wireless data access (including email, file transfer, and web browsing) at fairly low speeds, on the order of $20 \mathrm{Kbps}$. A strong market for these wide-area wireless data services never really materialized, due mainly to their low data rates, high cost, and lack of "killer applications". These services mostly disappeared in the 1990s, supplanted by the wireless data capabilities of cellular telephones and wireless local area networks (LANs). The introduction of wired Ethernet technology in the 1970's steered many commercial companies away from radio-based networking. 
In 1985 the Federal Communications Commission (FCC) enabled the commercial development of wireless LANs by authorizing the public use of the Industrial, Scientific, and Medical (ISM) frequency bands for wireless LAN products. The ISM band was very attractive to wireless LAN vendors since they did not need to obtain an FCC license to operate in this band. Moreover, the interference from primary users within this frequency band was quite high. As a result these initial wireless LANs had very poor performance in terms of data rates and coverage.

The current generation of wireless LANs, based on the family of IEEE 802.11 standards. Wired Ethernets today offer data rates of $100 \mathrm{Mbps}$, and the performance gap between wired and wireless LANs is likely to increase over time without additional spectrum allocation. Despite the big data rate differences, wireless LANs is becoming the preferred Internet access method in many homes, offices, and campus environments due to their convenience and freedom from wires. However, most wireless LANs support applications such as email and web browsing that are not bandwidth-intensive.

By far the most successful application of wireless networking has been the cellular telephone system. The roots of this system began in 1915, when wireless voice transmission between New York and San Francisco was first established. In 1946 public mobile telephone service was introduced in 25 cities across the United States: thirty years after the introduction of mobile telephone service the New York system could only support 543 users. A solution to this capacity problem emerged during the 50's and 60's when researchers at AT\&T Bell Laboratories developed the cellular concept. In 1947 AT\&T requested spectrum for cellular service from the FCC. The design was mostly completed by the end of the 1960's, the first field test was in 1978, and the FCC granted service authorization in 1982.

\section{WIRELESS VISION}

The vision of wireless communications supporting information exchange between people or devices is the communications frontier of the next few decades, and much of it already exists in some form. This vision will allow multimedia communication from anywhere in the world using a small handheld device or laptop. Wireless networks will connect palmtop, laptop, and desktop computers anywhere within an office building or campus, as well as from the corner cafe. In the home these networks will enable a new class of intelligent electronic devices that can interact with each other and with the Internet in addition to providing connectivity between computers, phones, and security/monitoring systems. Such smart homes can also help the elderly and disabled with assisted living, patient monitoring, and emergency response. Wireless entertainment will permeate the home and any place that people congregate. Video teleconferencing will take place between buildings that are blocks or continents apart, and these conferences can include travelers as well, from the salesperson who missed his plane connection to the CEO off sailing in the Caribbean. Wireless video will enable remote classrooms, remote training facilities, and remote hospitals anywhere in the world. Wireless sensors have an enormous range of both commercial and military applications. Commercial applications include monitoring of fire hazards, hazardous waste sites, stress and strain in buildings and bridges, carbon dioxide movement and the spread of chemicals and gasses at a disaster site. These wireless sensors self-configure into a network to process and interpret sensor measurements and then convey this information to a centralized control location. Military applications include identification and tracking of enemy targets, detection of chemical and biological attacks, support of unmanned robotic vehicles, and counter-terrorism. Finally, wireless networks enable distributed control systems, with remote devices, sensors, and actuators linked together via wireless communication channels. Such networks enable automated highways, mobile robots, and easily-reconfigurable industrial automation.

\section{$1 G$}

The first commercially automated cellular network (the $1 \mathrm{G}$ generation) was launched in Japan by NTT in 1979, initially in the metropolitan area of Tokyo. Within five years, the NTT network had been expanded to cover the whole population of Japan and became the first nationwide $1 \mathrm{G}$ network. In 1981, this was followed by the simultaneous launch of the Nordic Mobile Telephone (NMT) system in Denmark, Finland, Norway and Sweden. NMT was the first mobile phone network featuring international roaming. The first $1 \mathrm{G}$ network launched in the USA was Chicago-based Ameritech in 1983 using the Motorola DynaTAC mobile phone. Several countries then 
followed in the early-to-mid 1980s including the UK, Mexico and Canada. The first analog cellular system deployed in Chicago in 1983 was already saturated by 1984.

2G

The second generation of cellular systems, first deployed in the early 1990's, were based on digital communications. While second generation cellular systems initially provided mainly voice services, these systems gradually evolved to support data services such as email, Internet access, and short messaging. Unfortunately, the great market potential for cellular phones led to a proliferation of second generation cellular standards: three different standards in the U.S. alone, and other standards in Europe and Japan, all incompatible. Thanks to 2G networks, it is possible to transmit voice and low volume digital data, for example text messages (SMS, for Short Message Service) or multimedia messages (MMS, for Multimedia Message Service). The GSM standard allows a maximum data rate of $9.6 \mathrm{kbps}$.

\section{G}

International Mobile Telecommunications-2000 (IMT - 2000), better known as 3G or 3rd Generation, is a generation of standards for mobile phones and mobile telecommunications services fulfilling specifications by the International Telecommunication Union. ${ }^{[1]}$ Application services include wide-area wireless voice telephone, mobile Internet access, video calls and mobile TV, all in a mobile environment. Compared to the older $2 \mathrm{G}$ and $2.5 \mathrm{G}$ standards, a $3 \mathrm{G}$ system must provide peak data rates of at least $200 \mathrm{kbit} / \mathrm{s}$ according to the IMT2000 specification. Recent $3 \mathrm{G}$ releases often denoted $\underline{3.5 \mathrm{G}}$ and $\underline{3.75 \mathrm{G}}$, also provide mobile broadband access of several $\underline{\text { Mbit/s }}$ to laptop computers and Smartphone's.

High transmission data rate:

- $\quad 144 \mathrm{Kbps}$ with total coverage for mobile use

- $\quad 384 \mathrm{Kbps}$ with medium coverage for pedestrian use

- 2 Mbps with reduced coverage area for stationary use

4G

LTE Advanced (Long-term-evolution Advanced) is a candidate for IMT-Advanced standard, formally submitted by the 3GPP organization to ITU-T in the fall 2009, and expected to be released in 2012. The target of 3GPP LTE Advanced is to reach and surpass the ITU requirements. ${ }^{[14]}$ LTE Advanced is essentially an enhancement to LTE. It is not a new technology but rather an improvement on the existing LTE network. This upgrade path makes it more cost effective for vendors to offer LTE and then upgrade to LTE Advanced which is similar to the upgrade from WCDMA to HSPA. LTE and LTE Advanced will also make use of additional spectrum and multiplexing to allow it to achieve higher data speeds. Coordinated Multi-point Transmission will also allow more system capacity to help handle the enhanced data speeds. Release 10 of LTE is expected to achieve the LTE Advanced speeds. Release 8 currently supports up to $300 \mathrm{Mbit} / \mathrm{s}$ download speeds which is still short of the IMTAdvanced standards.

The pre-4G technology 3GPP Long Term Evolution (LTE) is often branded "4G", but the first LTE release does not fully comply with the IMT-Advanced requirements. LTE has a theoretical net bit rate capacity of up to $100 \mathrm{Mbit} / \mathrm{s}$ in the downlink and $50 \mathrm{Mbit} / \mathrm{s}$ in the uplink if a $20 \mathrm{MHz}$ channel is used - and more if multiple-input multiple-output (MIMO), i.e. antenna arrays, are used. The world's first publicly available LTE service was opened in the two Scandinavian capitals Stockholm (Ericsson system) and Oslo (a Huawei system) on 14 December 2009, and branded 4G. The user terminals were manufactured by Samsung. Currently, the two publicly available LTE services in the United States are provided by Metro PCS, and Verizon Wireless. AT\&T also has an LTE service in the works. 


\section{TECHNICAL ISSUES}

Many technical challenges must be addressed to enable the wireless applications of the future. These challenges extend across all aspects of the system design. As wireless terminals add more features, these small devices must incorporate multiple modes of operation to support the different applications and media. Computers process voice, image, text, and video data, but breakthroughs in circuit design are required to implement the same multimode operation in a cheap, lightweight, handheld device. Since consumers don't want large batteries that frequently need recharging, transmission and signal processing in the portable terminal must consume minimal power. The signal processing required to support multimedia applications and networking functions can be powerintensive.

\section{CURRENT WIRELESS SYSTEMS}

This section provides a brief overview of current wireless systems in operation today. The design details of these systems are constantly evolving, with new systems emerging and old ones going by the wayside. Thus, we will focus mainly on the high-level design aspects of the most common systems.

\section{Wireless LANs}

Wireless LANs provide high-speed data within a small region, e.g. a campus or small building, as users move from place to place. Wireless devices that access these LANs are typically stationary or moving at pedestrian speeds. All wireless LAN standards in the U.S. operate in unlicensed frequency bands. The primary unlicensed bands are the ISM bands at $900 \mathrm{MHz}, 2.4 \mathrm{GHz}$, and $5.8 \mathrm{GHz}$, and the Unlicensed National Information Infrastructure band at $5 \mathrm{GHz}$.

\section{Wide Area Wireless Data Services}

Wide area wireless data services provide wireless data to high-mobility users over a very large coverage area. In these systems a given geographical region is serviced by base stations mounted on towers, rooftops, or mountains. The base stations can be connected to a backbone wired network or form a multihop ad hoc wireless network. Initial wide area wireless data services had very low data rates, below $10 \mathrm{Kbps}$, which gradually increased to $20 \mathrm{Kbps}$.

\section{Broadband Wireless Access}

Broadband wireless access provides high-rate wireless communications between a fixed access point and multiple terminals. These systems were initially proposed to support interactive video service to the home, but the application emphasis then shifted to providing high speed data access (tens of Mbps) to the Internet, the WWW, and to high speed data networks for both homes and businesses. In the U.S. two frequency bands were set aside for these systems: part of the $28 \mathrm{GHz}$ spectrum for local distribution systems (local multipoint distribution systems or LMDS) and a band in the $2 \mathrm{GHz}$ spectrum for metropolitan distribution systems (multichannel multipoint distribution services or MMDS). LMDS represents a quick means for new service providers to enter the already stiff competition among wireless and wireline broadband service providers. Data rates of around $40 \mathrm{Mbps}$ will be available for fixed users and 15 Mbps for mobile users, with a range of several kilometers. Many laptop and PDA manufacturers are planning to incorporate WiMAX once it becomes available to satisfy demand for constant Internet access and email exchange from any location. WiMax will compete with wireless LANs, $3 \mathrm{G}$ cellular services, and possibly wireline services like cable and DSL. The ability of WiMax to challenge or supplant these systems will depend on its relative performance and cost, which remain to be seen.

\section{Satellite Networks}

Commercial satellite systems are another major component of the wireless communications infrastructure. The most appealing use for satellite system is broadcasting of video and audio over large geographic regions. In the U.S. approximately 1 in 8 homes have direct broadcast satellite service, and satellite radio is emerging as a popular 
service as well. Similar audio and video satellite broadcasting services are widespread in Europe. Satellites are best tailored for broadcasting, since they cover a wide area and are not compromised by an initial propagation delay. Moreover, the cost of the system can be amortized over many years and many users, making the service quite competitive with terrestrial entertainment broadcasting systems.

\section{LOW-COST LOW-POWER RADIOS: BLUETOOTH AND ZIGBEE}

As radios decrease their cost and power consumption, it becomes feasible to embed them in more types of electronic devices, which can be used to create smart homes, sensor networks, and other compelling applications. Two radios have emerged to support this trend: Bluetooth and Zigbee. Bluetooth radios provide short range connections between wireless devices along with rudimentary networking capabilities. The Bluetooth standard is based on a tiny microchip incorporating a radio transceiver that is built into digital devices. The transceiver takes the place of a connecting cable for devices such as cell phones, laptop and palmtop computers, portable printers and projectors, and network access points. Bluetooth is mainly for short range communications, e.g. from a laptop to a nearby printer or from a cell phone to a wireless headset. Its normal range of operation is $10 \mathrm{~m}$ (at $1 \mathrm{~mW}$ transmit power), and this range can be increased to $100 \mathrm{~m}$ by increasing the transmit power to $100 \mathrm{~mW}$. The system operates in the unlicensed $2.4 \mathrm{GHz}$ frequency band.

The Bluetooth standard is named after Harald I Bluetooth, the king of Denmark between 940 and 985 AD who united Denmark and Norway.

\section{CONCLUSION}

Considering the rate at which so many things are being connected wirelessly to the Internet, it's becoming easier to imagine how cellular connectivity is expect to signal traffic to and from 50 billion emerging devices within the next decade. While wireless carriers, chipset manufacturers, tower owners and infrastructure vendors have a lot to be excited about, there is also a growing prospect of greater Wi-Fi adoption. The technology, which distinguishes itself as one that runs on unlicensed spectrum, has been growing steadily and is increasingly seen as a fill-in alternative for certain locations where cellular signals are either too weak or too complex and ineffective due to cost.

\section{AUTHOR INFORMATION}

Dr. Tom Seymour - Professor, Management Information Systems - Minot State University - Minot, ND. Dr. Tom Seymour was appointed to Chair the Business Information Technology Department at Minot State University, Minot, North Dakota for the 2007-2009 year. He has been a faculty member at MSU for 26 years. Dr. Seymour graduated from Mayville (BS), UND (MA), and Colorado State University (PhD). He came to Minot State University from Murray, Kentucky after teaching in 7 states. He is a native of Cavalier, North Dakota. He has given over 150 Computer / E-Commerce presentations in 41 states and 10 foreign countries. Dr. Seymour teaches technology classes in the classroom and via the Internet. Tom is a HLC/ NCA peer reviewer and has reviewed in 19 states including Singapore, Mexico and China. His publication record includes publishing over 80 articles in refereed journals and editing many proceedings and college textbooks. For five years Tom wrote an Internet column for the Minot Daily News and he was a North Dakota State Senator (2002-2010)

Ali Shaheen is working in Dallas, TX as an Assistant Project Manager in the telecommunications sector. He has been working the last 7 years in the Information Technology and Telecommunications industries across Asia and North America. He was born in Pakistan and completed Engineering and MBA degrees in Pakistan. Currently, he will complete a Master's Degree in Management Information Systems at Minot State University in Minot, North Dakota and then pursue a career in Project Management.

\section{REFERENCES}

1. $\quad$ www.wikipedia.org

2. http://www.wirelessweek.com/tags/technology/ 
3. http://www.rcrwireless.com/article/20110301/DEVICES/110229963/emerging-devices-and-the-internet-ofthings

4. T. S. Rappaport. Wireless Communications: Principles and Practice, 2nd ed. Prentice Hall.

5. $\quad$ W. Stallings, Wireless Communications and Networks, 2nd Ed., Prentice Hall.

6. K. Pahlavan and P. Krishnamurthy, Principles of Wireless Networks A Unified Approach, New Jersey: Prentice.

7. $\quad$ V.H. McDonald, "The Cellular Concept," Bell System Tech. J.

8. S. Schiesel. Paging allies focus strategy on the Internet.

9. $\quad$ F. Abrishamkar and Z. Siveski, "PCS global mobile satellites," IEEE Commun. Mag.

10. R. Ananasso and F. D. Priscoli, "The role of satellites in personal communication services," Issue on Mobile.

11. Satellite Communications for Seamless PCS, IEEE J. Sel. Areas Commun. 